\title{
Development in Laser Peening of Advanced Ceramic
}

\author{
Pratik Shukla*a, Graham C. Smith ${ }^{\mathrm{b}}$, David G. Waugh ${ }^{\mathrm{a}}$, Jonathan Lawrence \\ ${ }^{a}$ University of Chester, Dept of Mech Engineering, Laser Engineering and Manufacturing Research \\ Group, Faculty of Science and Engineering, Thornton Science Park, Chester, CH2 4NU, UK; \\ ${ }^{b}$ University of Chester, Dept of Natural Sciences, Laser Engineering and Manufacturing Research \\ Group, Faculty of Science and Engineering, Thornton Science Park, Chester, CH2 4NU, UK
}

\begin{abstract}
Laser peening is a well-known process applicable to surface treat metals and alloys in various industrial sectors. Research in the area of laser peening of ceramics is still scarce and a complete laser-ceramic interaction is still unreported. This paper focuses on laser peening of $\mathrm{Al}_{2} \mathrm{O}_{3}$ ceramics employed for cutting tools, armor plating, dental and biomedical implants, with a view to elucidate the unreported work. A detailed investigation was conducted with 1064nm Nd:YAG ns pulse laser to first understand the surface effects, namely: the topography, hardness, $\mathrm{K}_{\mathrm{Ic}}$ and the microstructure of $\mathrm{Al}_{2} \mathrm{O}_{3}$ advanced ceramics. The results showed changes in surface roughness and microstructural modification after laser peening. An increase in surface hardness was found by almost 2 folds, as the diamond footprints and its flaws sizes were considerably reduced, thus, enhancing the resistance of $\mathrm{Al}_{2} \mathrm{O}_{3}$ to better withstand mechanical impact. This inherently led to an enhancement in the $\mathrm{K}_{\mathrm{Ic}}$ by about $42 \%$. This is attributed to an induction of compressive residual stress and phase transformation. This work is a first-step towards the development of a 3-dimentional laser peening technique to surface treat many advanced ceramic components. This work has shown that upon tailoring the laser peening parameters may directly control ceramic topography, microstructure, hardness and the $\mathrm{K}_{\mathrm{Ic}}$. This is useful for increasing the performance of ceramics particularly for demanding applications particularly where it matters. Upon successful peening of bullet proof vests could result to higher ballistic strength and resistance against higher sonic velocity, which would not only prevent serious injuries, but could also help to save lives of soldiers on the battle fields.
\end{abstract}

Keywords: Laser Peening, $\mathrm{Al}_{2} \mathrm{O}_{3}$, Ceramics, Hardness, $\mathrm{K}_{\mathrm{lc}}$, Microstructure, Surface finish

\section{INTRODUCTION}

\section{Research rationale}

Surface treatment of metals and alloys by laser peening has been a successful technique for a number of years ${ }^{1-4}$. This is due to the benefits obtained by laser peening of metal/alloys in particular. The advantages offered by the process are, namely: increased residual compressive stress, reduction in frictional properties, wear rate, enhanced surface finish and hardness. However, laser peening of advance ceramics is still under-developed and scarce. This is because of their physical characteristics that prevent them from behaving in the same way as metals, especially, when exposed to short pulses of laser energy. In particular, it is difficult to bring about mechanical yielding and plastics deformation within ceramics. Therefore, it is difficult to gain any beneficial effects which are conventionally obtained on metals. As such, it is of a great interest to investigate the effects of laser peening on the advanced ceramics. Upon success, would first open new avenues for the use of ceramics in demanding applications, such as for ceramic armor plating and in conditions where high level of mechanical and thermal stress as well as in presence of a corrosive environment. Typical ceramic products in engineering such as high performance cutting tools namely: cutting knives, and machine tools could also benefit from laser peening. Secondly, this study would also enable one to understand the effects of the pulsed laser energy interaction with advanced ceramics such as alumina. Much work has been conducted in the area of laser peening of metallic parts ${ }^{5-6}$. Recent published work in this area has also evolved from the use of microsecond, nanosecond to shorter pulses being applied at both picosecond and femtosecond range on metals ${ }^{7-11}$. With that said, the only previous investigation that closely relates to the work in this study is that of Akita et.al. ${ }^{12}$. The work in their investigation involved the use of a Nd:YAG laser (532nm wavelength) to peen a $\mathrm{Si}_{3} \mathrm{~N}_{4}$ ceramics. They reported that plastic straining on the surface layer resulted to induction of compressive residual stress, with an increase in surface roughness, and an enhancement in bending stress. Having said

*p.shukla@ chester.ac.uk; phone +44(0)7739461805; +44(0)1244512559; www.chesterlasers.org 
that, the research herein is still very important because the reporting's made by Akita et.al were first, only, for a $\mathrm{Si}_{3} \mathrm{~N}_{4}$ ceramic. Also, an important property such as hardness, $\mathrm{K}_{\mathrm{Ic}}$, or microstructural modification was not examined to verify the residual stress within the surface and the subsurface. Moreover, no evidence of a material integrity was reported. This work is a first-step towards developing a laser peening process of ceramics and to understand the effects of laser peening from a physical characteristics, namely: surface topography; hardness; fracture toughness parameter $\mathrm{K}_{\mathrm{Ic}}$; residual stress and the microstructure of the laser peened $\mathrm{Al}_{2} \mathrm{O}_{3}$, to not only fill the gap in knowledge but with a view to provide a strengthening technique for enhancing the service life of various ceramic components.

\section{Laser Peening Fundamentals}

Technically, effective laser peening of materials depends on the introduction of a plasma produced during laser-material interaction. In most instances, this is created by supplying a thin layer of water on to the work-piece as shown in Figure 1. The plasma enables the absorption of the radiated laser energy to create sufficient pressure that is generally measured in 100 s of atmospheres ${ }^{6-10,13}$. Thus, the local distribution of high energy is further absorbed into the material and produces a circular indentation, depending on the shape of the laser beam. The incident laser energy and the generated plasma, consequently, produces sufficient level of shock-wave within the surface and the sub-surface of the material. This creates thermal expansion into the material and deems the material under compression within the laser affected region. The laser peening process requires precise control and the induction of correct energy density. Over peening may result to generation of tensile stresses or the possibility of drilling into the material which defeats the objective. Typically, laser beam absorption also depends on the particular wavelength applied at the material surface. Particularly for ceramics, laser in the range of $1 \mu \mathrm{m}$ wavelength and under, tends to produce sufficient absorption ${ }^{14-17}$.

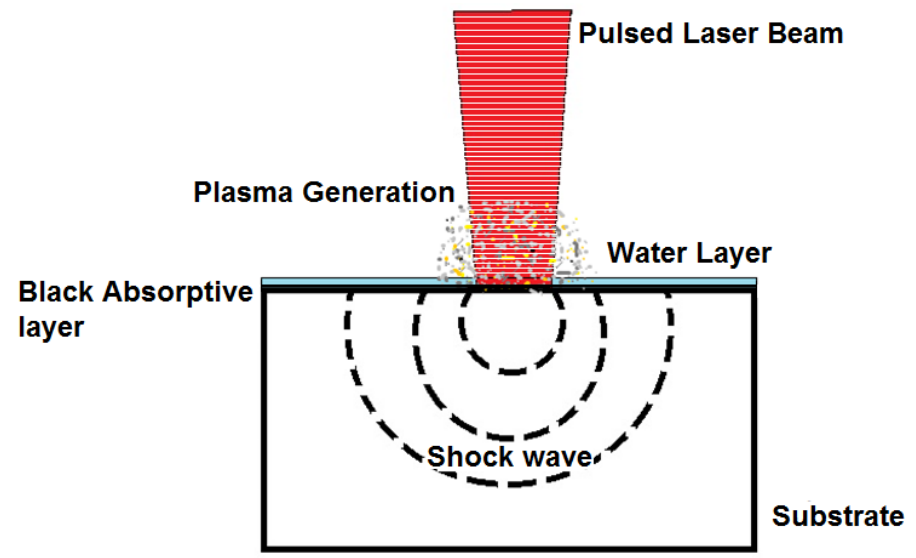

Figure 1 A schematic showing the features involved in effective laser peening of materials in general.

\section{EXPERIMENTATION AND METHODOLOGY}

A cold issotatically pressed (CIPed) $\mathrm{Al}_{2} \mathrm{O}_{3}$ advanced ceramic was used as an experimental material from Shanghai Unite Technology (Shanghai, China) with the dimension $50 \mathrm{~mm} \times 10 \mathrm{~mm} \times 5 \mathrm{~mm}$ bar as shown in Figure 2(a). The advanced $\mathrm{Al}_{2} \mathrm{O}_{3}$ ceramic comprised of $99.5 \% \mathrm{Al}_{2} \mathrm{O}_{3}$ and $0.5 \%$ unspecified CIPed at 455 bar pressure from all of its orientations and sintered at $1200{ }^{\circ} \mathrm{C}$ for 5 hours (as specified by the manufacturer). The ceramic was mechanically and microstructurally characterized prior to all experimentation. The average as-received surface finish (from 5 samples) was Ra $1.53 \mu \mathrm{m}$. The surface hardness was measured to be $1276 \mathrm{HV}$ and a plane strain fracture toughness $\left(\mathrm{K}_{\mathrm{Ic}}\right)$ was determined as $2.31 \mathrm{MPa} \cdot \mathrm{m}^{1 / 2}$.

The laser used in this investigation was a pulsed Nd:YAG laser (Continuum; Powerlite; DLS 8000; San Jose; USA) as shown in Figure 2. This emitted a 1064nm wavelength with laser energy applied ranging from a minimum of $30 \mathrm{~mJ}$ to a maximum of $966 \mathrm{~mJ}$. Thereafter, the effects were examined using an optical microscope and an SEM (see Figure 2(d) for details). A pulse repetition rate (PRR) of $10 \mathrm{~Hz}$ and a pulse duration of $6 \mathrm{~ns}$ was delivered as a single shot to the surface of the $\mathrm{Al}_{2} \mathrm{O}_{3}$. The laser beam comprised of a flat-top profile and a divergence angle of $0.45 \mathrm{mrad}$. As this was a first stepstudy, the laser beam was simply delivered with a raw laser spot diameter of $9.5 \mathrm{~mm}$ and was sufficient to affect the ceramic due to its low divergence and high brightness. No assist gas was used for the laser peening. In addition, laser peening is often conducted using an absorptive surface layer over the material and is also a water assisted technique ${ }^{12,14}$. 
The work herein, have employed the laser alone technique as the absorptive layer could melt and adhere to the ceramic and water assisted peening and laser alone peening both warrant individual investigations. However, our future investigations involve the use of such techniques to understand their individual effects respectively. Five samples were used for the experiments in order to evaluate the effect of laser peening on the $\mathrm{Al}_{2} \mathrm{O}_{3}$. Laser energy was recorded using an energy meter which enabled to measure the energy fluctuations of $\pm 3 \mathrm{~mJ}$, recorder for $30 \mathrm{sec}$ duration. Figure 2(b) show a footprint of the $9.5 \mathrm{~mm}$ spot on a laser burn paper prior to conducting the main experiments and Figure 2(c) shows the effects in varying the laser energy on the $\mathrm{Al}_{2} \mathrm{O}_{3}$ advanced ceramic. Surface finish and topography was examined using a chromatic confocal imaging device (3-D Surface Profiler; Micromeasure 2; Polytec Ltd; Hertfordshire; England). Vickers indentation tests were carried out with 7.5Kg indentation load (VHTM 2000; Vickers Ltd. Engineering Group; Sheffield; England). All crack lengths were observed using an optical microscopy and scanning electron microscope (SEM) by Leo1455VP; Cambridge, England. Fracture toughness parameter $\mathrm{K}_{\mathrm{Ic}}$ was determined based on the methodology in our previous publication ${ }^{15}$.

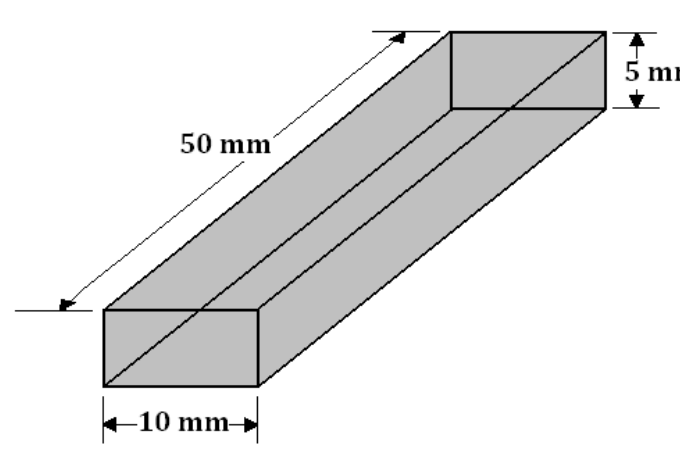

(a)

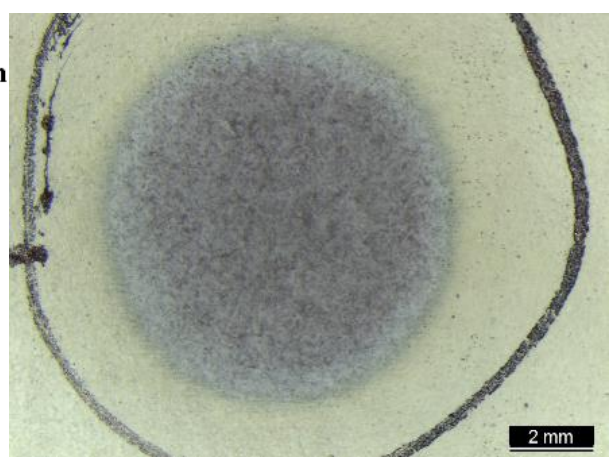

(b)

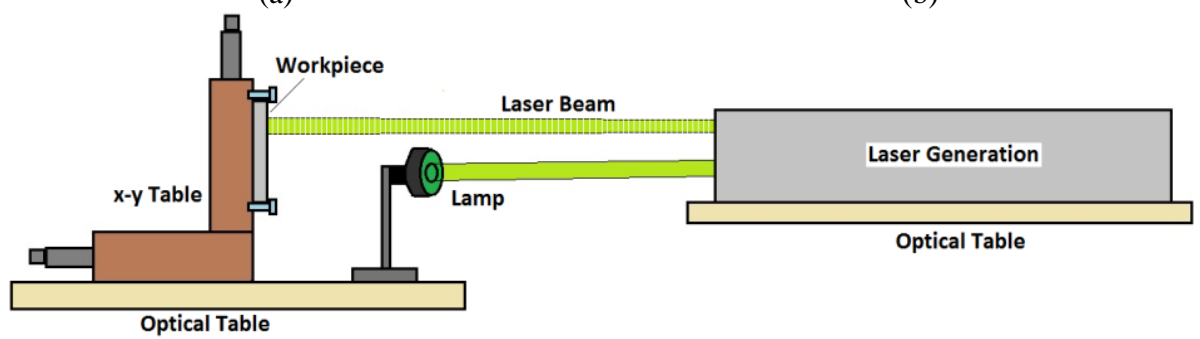

(c)

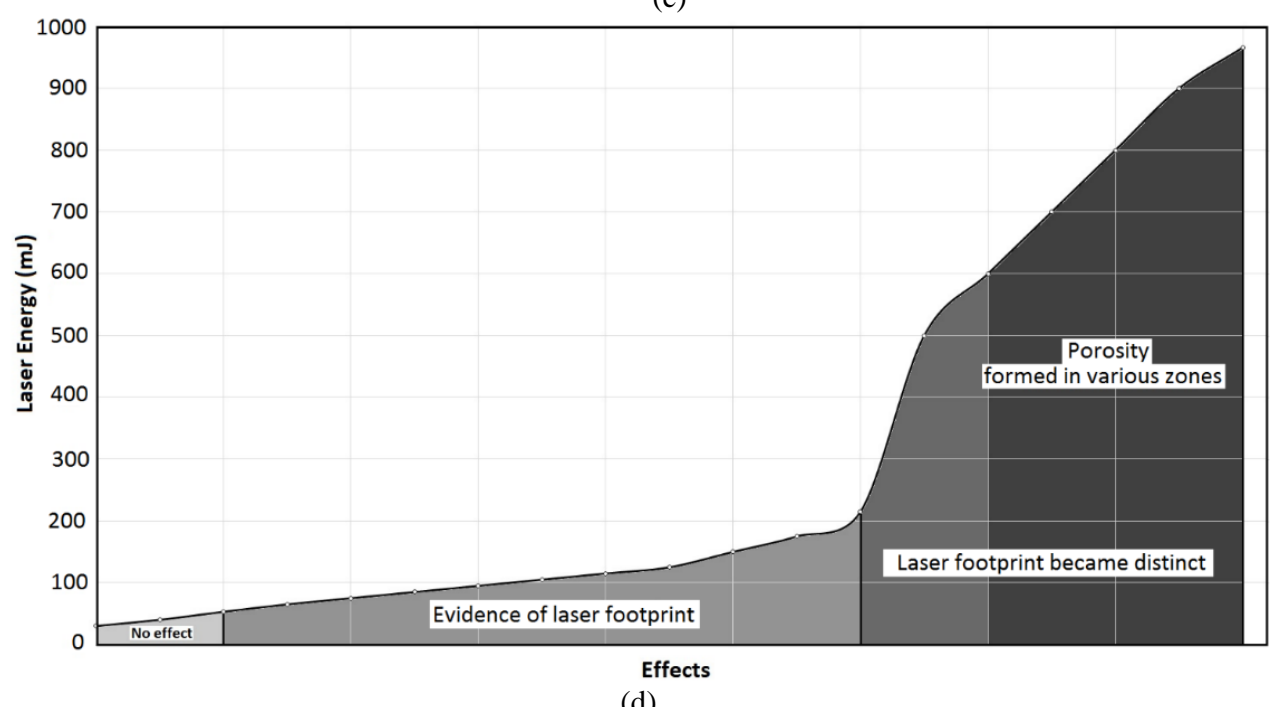

(d)

Figure 2. A schematic of the $\mathrm{Al}_{2} \mathrm{O}_{3}$ advanced ceramic work-piece in (a); an optical image of the $8.5 \mathrm{~mm}$ laser beam foot-print at 966 $\mathrm{mJ}, 10 \mathrm{~Hz}$ PRR, for $6 \mathrm{~ns}$ pulse duration, directed on a burn paper shown at x100 resolution in (b); the experimental set-up in (c); and (d) a graphical representation of the surface effects with respect to increase in laser energy. 


\section{RESULTS AND DISCUSSION}

\section{Topography}

All surface measurements were conducted over 3 individual sample of $\mathrm{Al}_{2} \mathrm{O}_{3}$ each condition. The arithmetic mean deviation of the surface roughness profile $(\mathrm{Ra})$ was measured to be $1.53 \mu \mathrm{m}$ for the as-received $\mathrm{Al}_{2} \mathrm{O}_{3}$. Comparatively, the average Ra value for the laser peened surfaces were up to and in some instances over, by 3 folds, as shown in Table 1 and Figure 3(a) to (d). This is generally expected with laser peening of metallic materials and could also be predicted/tailored, based on the material removal phenomena during laser pulse processing. What is interesting is that the surface roughness and material removal decreased with increasing applied laser energy. Generally, ablation rates are thought to be higher with increase in laser energy removing material through vaporization ${ }^{18}$. Thus, increases the roughness through higher material removal rate. This was however, not the case herein. Based on the difference in our results in comparison to the conventional effects that take place during laser peening of metals, the decreasing surface roughness with increasing laser energy was attributed to the removal of machined striations that were present over the $\mathrm{Al}_{2} \mathrm{O}_{3}$ advanced ceramic. A considerable level of machining marks were initially present in the as-received surface (refer to microstructural study) that were eliminated after laser peening. This in turn deemed the laser surface to become smoother at $966 \mathrm{~mJ}$ compared to the surface laser peened at $216 \mathrm{~mJ}$ and $600 \mathrm{~mJ}$.

Table 1. Showing the average surface roughness of the $\mathrm{Al}_{2} \mathrm{O}_{3}$ as-received surface and the laser peened surfaces.

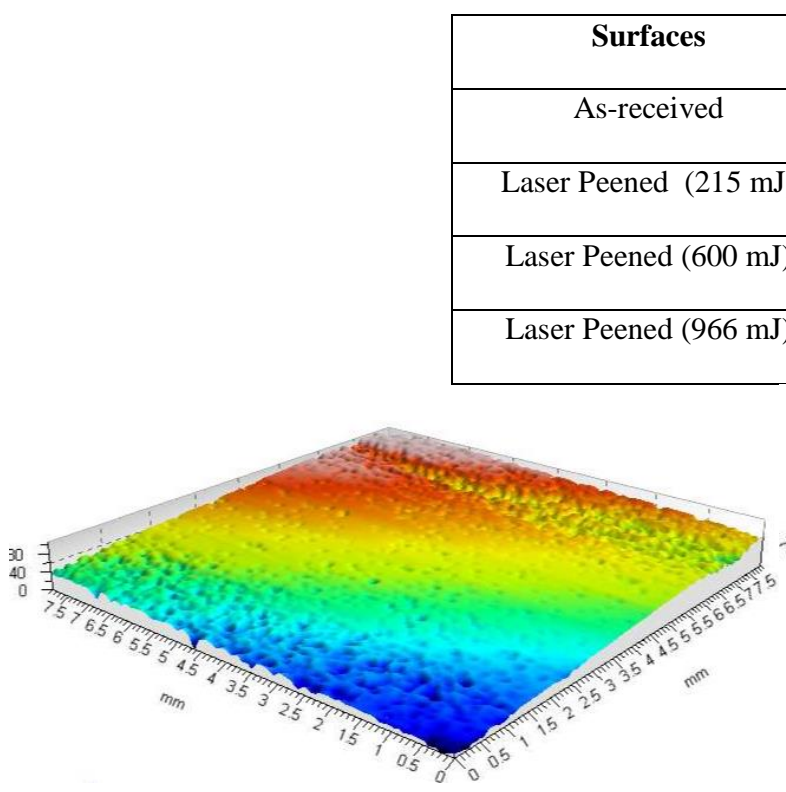

(a)

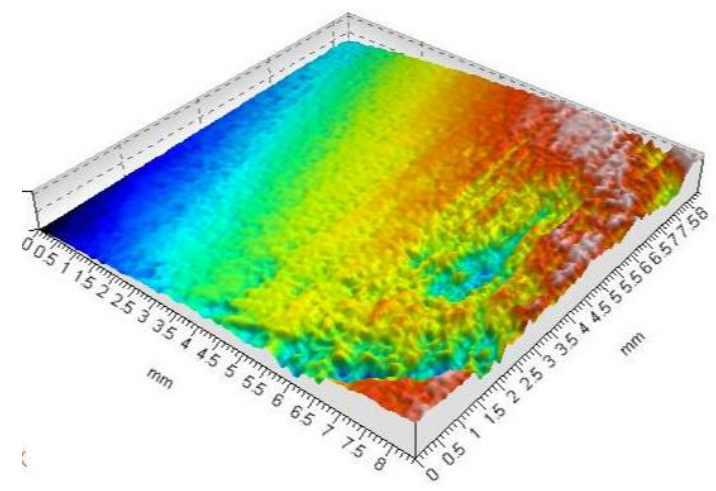

(c)

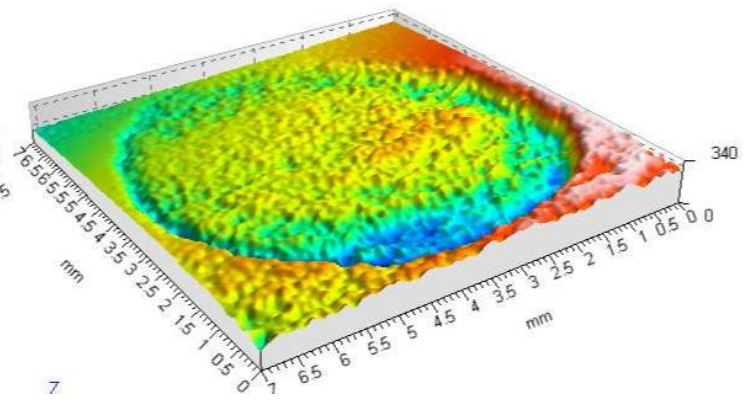

(b)

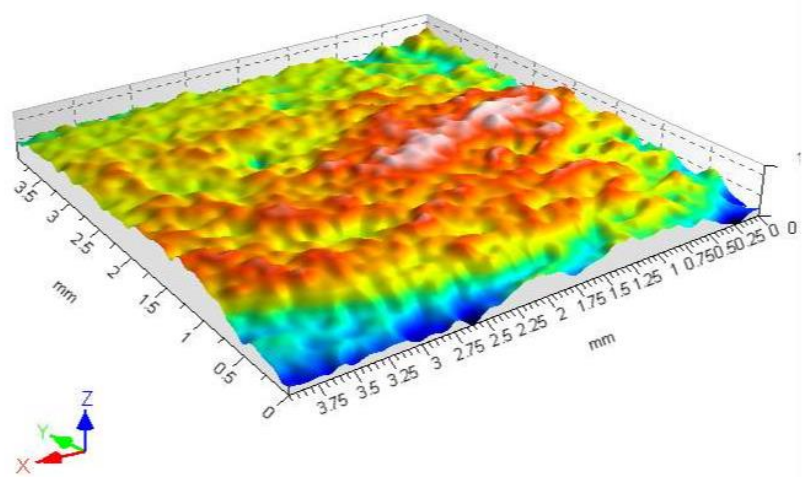

(d)

Figure 3. Surface profile images of the $\mathrm{Al}_{2} \mathrm{O}_{3}$ as-received surface in (a); and the laser peened surface applied with $215 \mathrm{~mJ}$ in (b); $600 \mathrm{~mJ}$ in (c); and $966 \mathrm{~mJ}$ in (d). 


\section{Microstructural Modification}

Figure 4(a) and (b) shows an optical image of the $8.5 \mathrm{~mm}$ diameter laser spot. With increasing power the spot diameter becomes more evident on the surface of the $\mathrm{Al}_{2} \mathrm{O}_{3}$. Using higher laser power in the range of $800 \mathrm{~mJ}$ to $966 \mathrm{~mJ}$, it was possible to see the maximum footprint of the beam. Figure 5(a) illustrates the optical images of the as-received surface in (a) and the laser peened surface in (b) to (d) with increasing laser power, whilst the repetition rate, spot size and the pulse duration were kept constant to $10 \mathrm{~Hz}, 8.5 \mathrm{~mm}$ and $6 \mathrm{~ns}$. As evident from the optical images, the by increasing the laser energy, the effect on the $\mathrm{Al}_{2} \mathrm{O}_{3}$ ceramic become somewhat distinct. This is particularly evident when the laser treated surfaces were compared to the as-received surface. The as-received surface in some areas showed evidence of machining marks such as striations, and micro-pores (also later evident from the SEM images). With increasing laser energy, the machining marks and striations were no longer apparent and the laser energy showed increasing level of ablation over the laser irradiated zone. Particularly at $850 \mathrm{~mJ}$ and $966 \mathrm{~mJ}$ resulted to enough ablation, which in turn, opened some surface pores.

The SEM micrographs in Figure 6(a) to (d) also confirm that the increasing laser energy created a significant change to the microstructure. At $215 \mathrm{~mJ}$, significant level of microstructural change is not apparent. However, one can see that elimination of pre-existing features at $600 \mathrm{~mJ}$ and were further distinctive at $966 \mathrm{~mJ}$ in Figure $6(\mathrm{c})$ and (d). Having said that, opening of pores and voids at the maximum laser energy could be attributed to the laser pulse ablating some of the material and exposing the surface defects. This goes to show that undesirable feature and surface free from defects can be readily obtained using laser peening energy around $600 \mathrm{~mJ}$ at the applied conditions. In terms of investigating the grain boundaries, the ceramic is required to be etched by chemical or thermal means so that the grains boundary conditions prior to and after laser peening could be examined in detail.

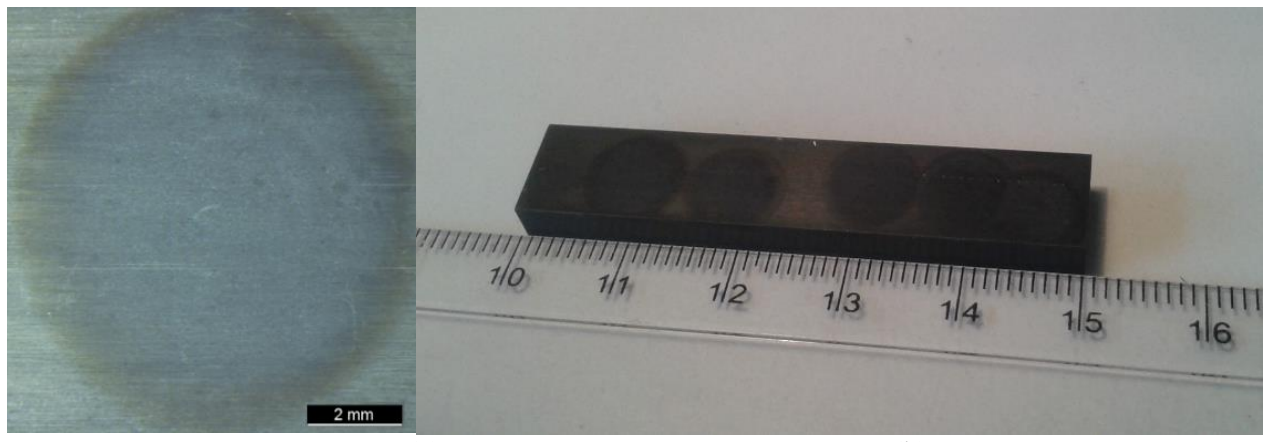

(a)

(b)

Figure 4. Optical images of the laser peened surface of $\mathrm{Al}_{2} \mathrm{O}_{3}$ advanced ceramic laser peened at $966 \mathrm{~mJ}, 10 \mathrm{~Hz}$, for $6 \mathrm{~ns}$ pulse duration with a single pulse in (a); and the actual workpiece with distributed peening in (b).

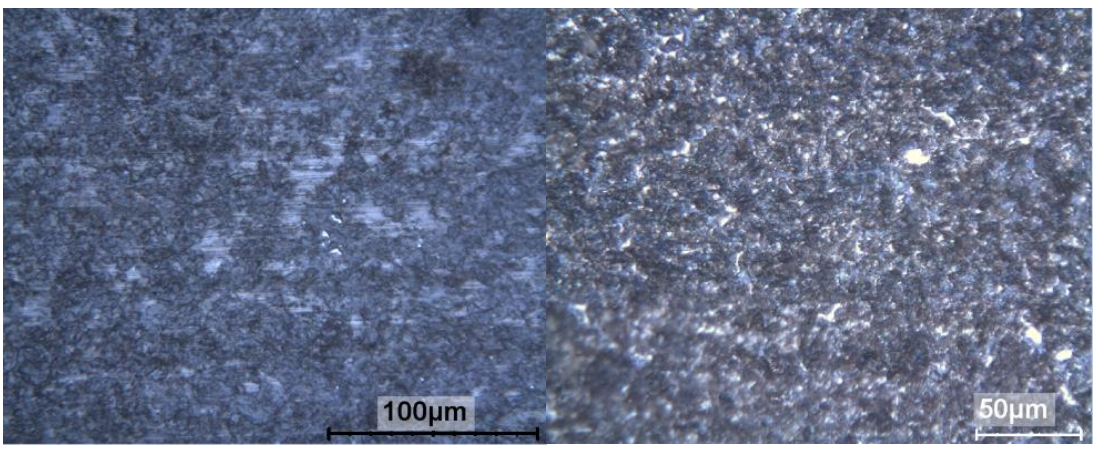

(a)

(b) 


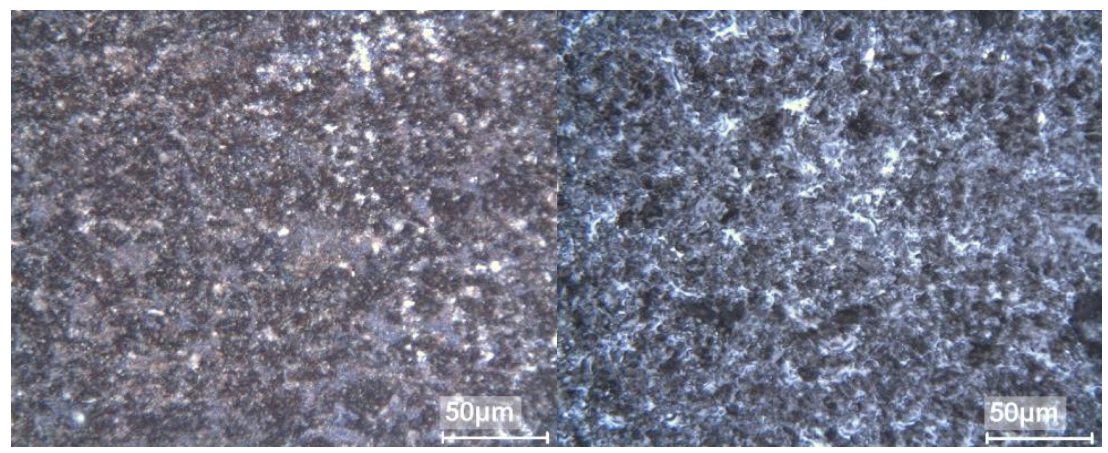

(c)

(d)

Figure 5. Optical images of the $\mathrm{Al}_{2} \mathrm{O}_{3}$ as-received surface in (a); $\mathrm{Al}_{2} \mathrm{O}_{3}$ surface irradiated at $215 \mathrm{~mJ}$ in (b); $\mathrm{Al}_{2} \mathrm{O}_{3}$ surface irradiated at $600 \mathrm{~mJ}$ in (c); and $\mathrm{Al}_{2} \mathrm{O}_{3}$ surface irradiated at $966 \mathrm{~mJ}$ in (d) at $8.5 \mathrm{~mm}$ spot size, using pulse duration of $6 \mathrm{~ns}$ and $10 \mathrm{~Hz}$ PRR shown at x50 resolution.

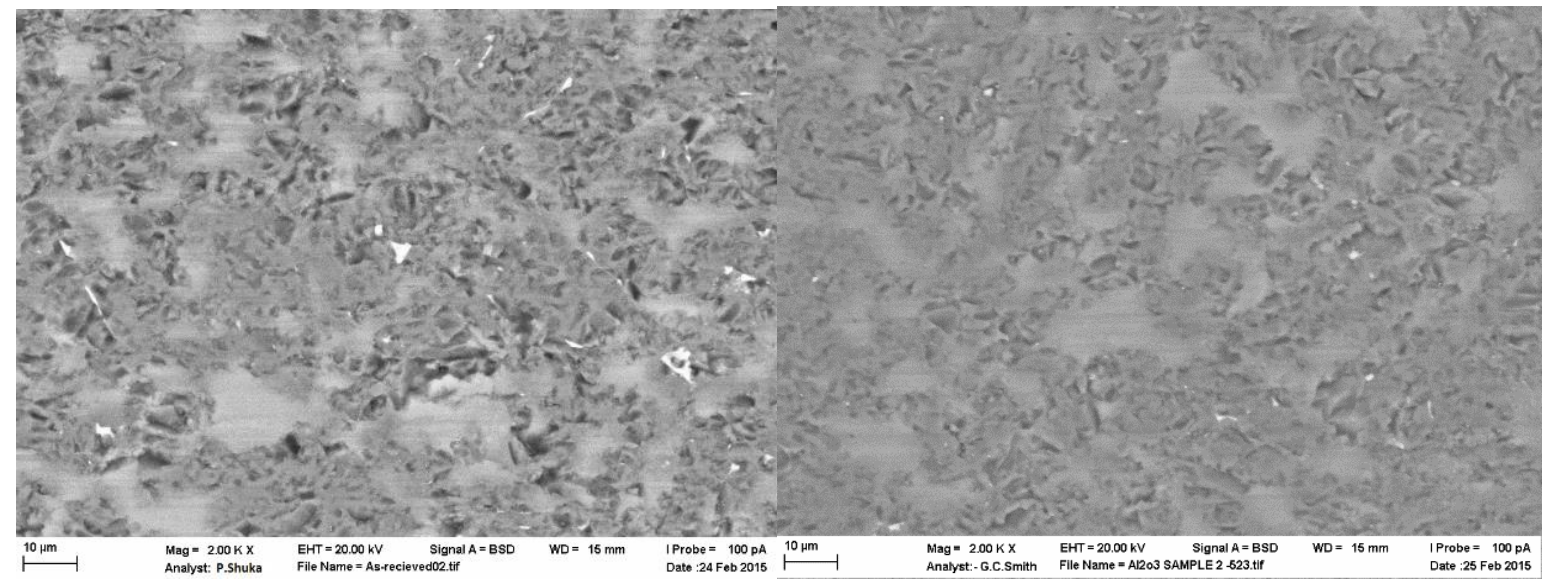

(a)

(b)

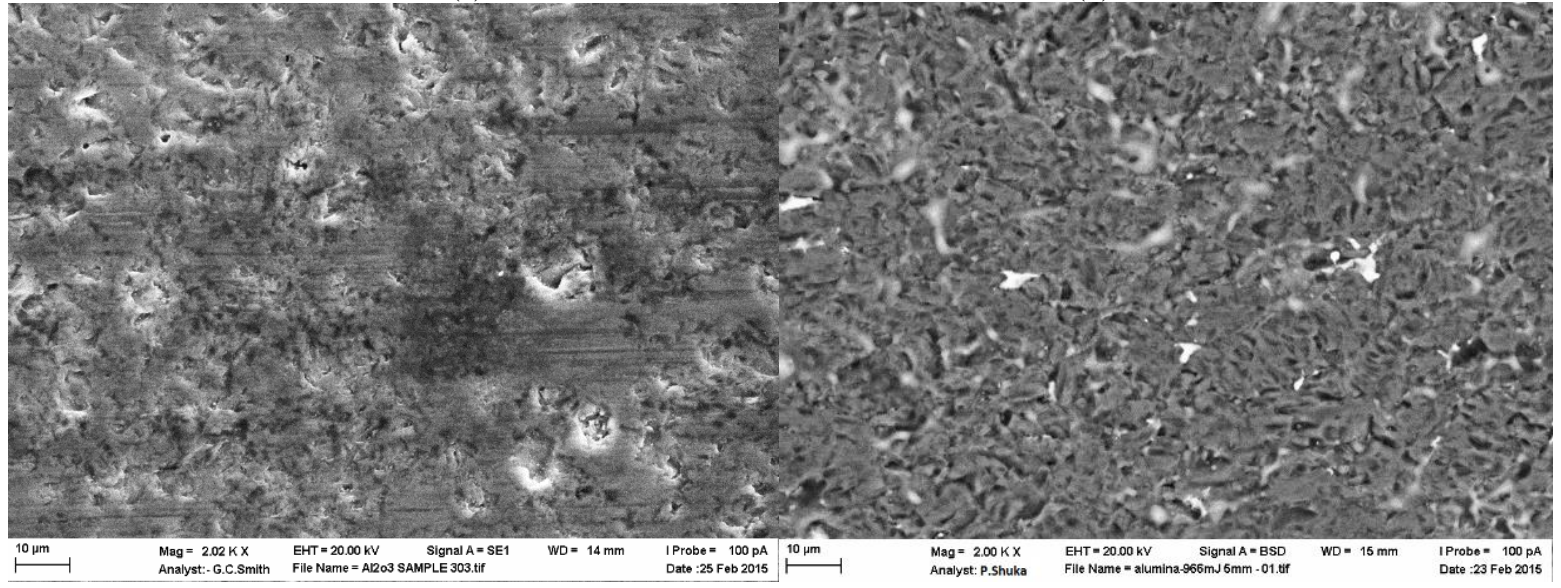

(c)

(d)

Figure $6 \mathrm{SEM}$ image of the $\mathrm{Al}_{2} \mathrm{O}_{3}$ as-received surface in (a), $\mathrm{Al}_{2} \mathrm{O}_{3}$ surface laser peened at $215 \mathrm{~mJ}$ in (b); peened at $600 \mathrm{~mJ}$ in (c); and $966 \mathrm{~mJ}$ in (d). 


\section{Indentation Response, Flaw Size, Hardness and Fracture Toughness Parameter - KIc}

Hardness measurements using the Vickers indentation technique showed that the starting as-received samples comprised of surface hardness of $1276 \mathrm{HV}$ from an average of 10 indentations tests. At the same time, the size of the Vickers diamond footprint was measured to be $212 \mu \mathrm{m}$ and the respective flaw size (from the edge of the diamond) were measured to be $217 \mu \mathrm{m}$ as shown in Figure 7(a) and (b). An increase in laser energy showed that the Vickers diamond footprints began to reduce by an average of $12 \mu \mathrm{m}$ at $215 \mathrm{~mJ}, 44 \mu \mathrm{m}$ at $600 \mathrm{~mJ}$ and finally at $32 \mu \mathrm{m}$ for $966 \mathrm{~mJ}$ of irradiation. But, in general, the results showed that laser peening increased the surface hardness in comparison to the as-received surface.

Furthermore, the flaw size for the diamond indents created on the laser peened surface were also smaller in comparison to the as-received surface. This indicated that the surface became less prone to cracking and showed resistance against mechanical impact despite the measured hardness to have shown significant rise, thus, increasing the brittleness. The Vickers diamond footprints also reduced in size considerably indicating that harder surface responded less in comparison to the softer surface during the Vickers indentation test. The hardness of the laser peened surfaces was measured to a maximum of $2037 \mathrm{HV}$ at $600 \mathrm{~mJ}$ and then $1677 \mathrm{HV}$ at $966 \mathrm{~mJ}$ as shown in Figure $7(\mathrm{c})$. Therefore, our interest in terms of future studies in this area may focus on the rationale for the change in hardness from $2037 \mathrm{HV}$ to $1677 \mathrm{HV}$ at $600 \mathrm{~mJ}$ and $966 \mathrm{~mJ}$ respectively. Albeit, the results in comparison to the as-received surface have clearly demonstrated a level of strengthening of the $\mathrm{Al}_{2} \mathrm{O}_{3}$ advanced ceramic as it is has become less prone to cracking and has shown a good response to Vickers indentation load impact of $7.5 \mathrm{Kg}$.

Furthermore, modification of the fracture toughness parameter $\mathrm{K}_{\mathrm{Ic}}$ is presented in Figure 7(d). The graph demonstrate an increase in $\mathrm{K}_{\mathrm{Ic}}$ from $2.32 \mathrm{MPa} \mathrm{m}^{1 / 2}$ (as-received surface) at $0 \mathrm{~mJ}$ to $2.60 \mathrm{MPa} \mathrm{m}^{1 / 2}$ at $215 \mathrm{~mJ}$ and $3.29 \mathrm{MPa} \mathrm{m}^{1 / 2}$ at $966 \mathrm{~mJ}$ respectively for the $\mathrm{Al}_{2} \mathrm{O}_{3}$ advanced ceramics. This revealed that the hardness, the respective flaw sizes and the $\mathrm{K}_{\mathrm{Ic}}$ could be tailored to suite a specific industrial need by optimizing the laser energy and the associated parameters in general.

Nonetheless, the surface hardening and the increasing fracture toughness could be attributed to an increase in residual stress compressive stress layer during laser peening. This compressive stress layer may form if dislocation motion was increased through plastic deformation at sub-micron level which then results to better indentation response under mechanical loading. Thus, resulting to less flaws on the diamond footprint as the acting tensile stress of the Vickers indenter must overcome the induced compressive stress under the laser peened area. Further analysis of the residual stress state under the laser peened spot, and through its cross-section should therefore be undertaken in future as this is generally an important aspect of both the mechanical and laser peening processes.

On this more, it is also postulated that surface strengthening resulted from a phase transformation of the $\mathrm{Al}_{2} \mathrm{O}_{3}$, whereby the alumina starting phase $\mathrm{M}+\mathrm{C}$ (mullite + cristobalite) would have transformed to a mullite $(\mathrm{M})$ phase, or alternatively, depending on the laser induced temperature, a phase change of $\mathrm{A}+\mathrm{M}$ (alumina + silicon dioxide) comprising of superior hardness and indentation response than the starting as-received surface of the $\mathrm{Al}_{2} \mathrm{O}_{3}$. In any case, the leading author of this paper suggests a full residual stress state and a phase transformation examination for deeper understanding of laser peening advanced ceramics. 


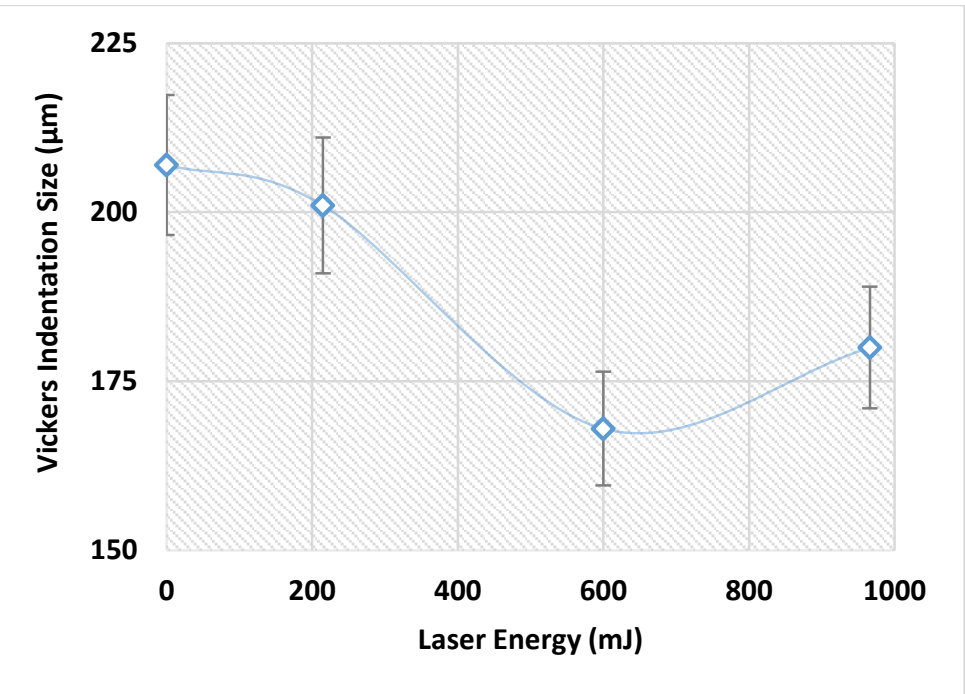

(a)

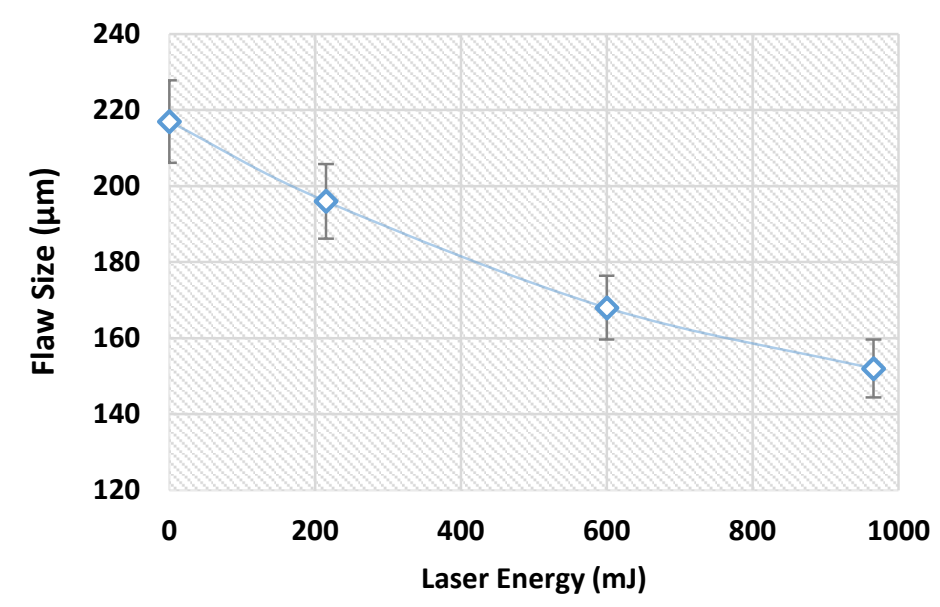

(b)

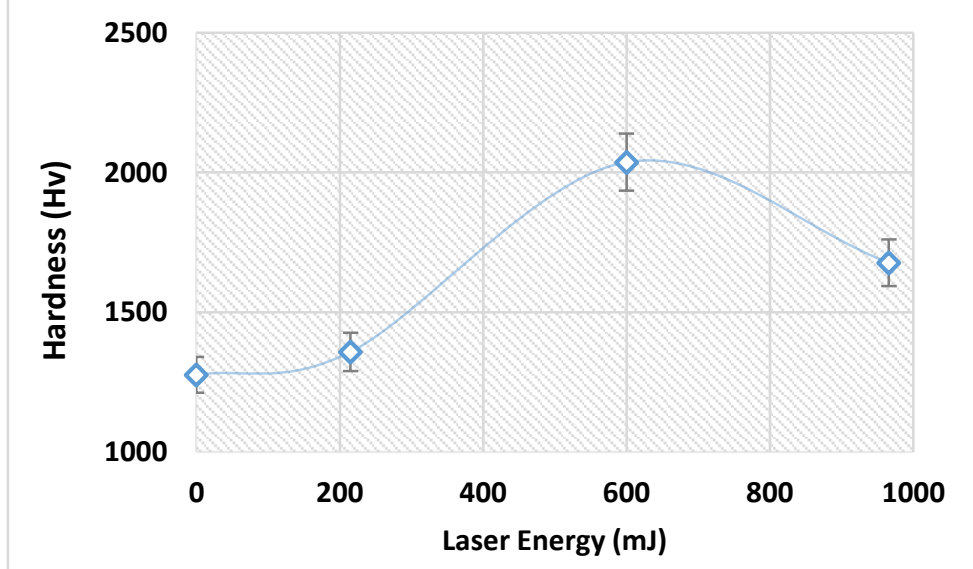

(c) 


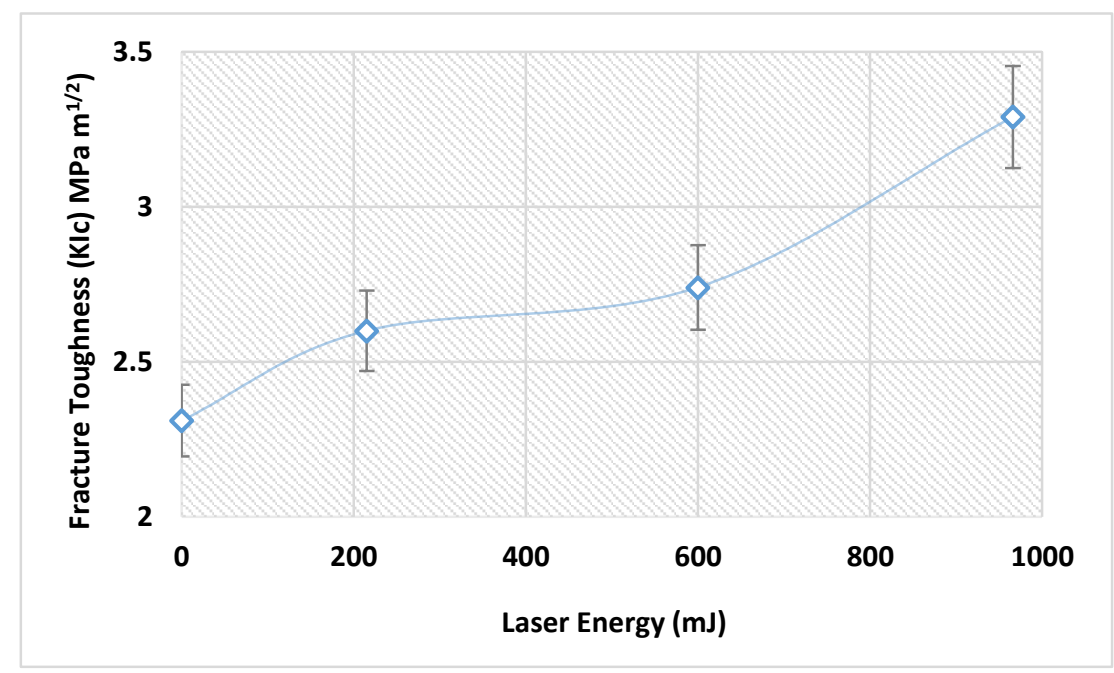

(d)

Figure 7. Graphical illustration showing Vickers indentation size in (a); change in hardness in (b); change in Vickers indentation induced flaw size in (c); and (d) the fracture toughness parameter $\mathrm{K}_{\mathrm{Ic}}$ for both the at as-received (0mJ) and the laser peened surfaces of the $\mathrm{Al}_{2} \mathrm{O}_{3}$ advanced ceramics.

\section{CONCLUSSIONS}

Laser peening of $\mathrm{Al}_{2} \mathrm{O}_{3}$ advanced ceramics was reported in this study for the first time. This is a first-step towards the development of a 3-dimentional laser peening process of many advanced ceramic components in various industrial sectors. The results herein have shown that it is possible to tailor the ceramic topography, microstructure, hardness and the $\mathrm{K}_{\mathrm{lc}}$ by inducing the required laser energy and associated laser parameters. This in turn could prove to be useful for increasing the performance of ceramics used for cutting tools; dental implants; tappet valves and pistons for automotive engines. Laser peening of ceramics could matter in particular for demanding applications such as for the surface treatment of armor plating, whereby, a successfully peening of bullet proof vest could result to higher ballistic strength and resistance against higher sonic velocity. This may not only prevent serious injuries, but could also help to save lives of soldiers on the battle fields. The results of this work demonstrate the following outcome:

1. Increase in surface roughness in comparison to the as-received surface. However, with increasing laser energy, the surface roughness reduced. This indicated that a level of melting and solidification at sub-micron level may have took place at the highest applied laser energy.

2. Considerable microstructural modification also resulted on the laser peened surfaces as the pre-existing surface defects were eliminated with increasing laser power, but surface pores and voids were exposed at the highest laser energy applied in various areas of the $\mathrm{Al}_{2} \mathrm{O}_{3}$ samples.

3. Hardness was increased from $1276 \mathrm{HV}$ to $2037 \mathrm{HV}$ on the laser irradiation zone at $600 \mathrm{~mJ}$, whist the hardness reduced to $1677 \mathrm{HV}$ at $966 \mathrm{~mJ}$ of applied laser energy. Nonetheless, all laser peened surfaces showed increase in hardness and reduction in the diamond footprints from the Vickers indentation test. Moreover, the flaw size of the diamond footprints were also reduced which goes to show that the laser peened $\mathrm{Al}_{2} \mathrm{O}_{3}$ responded better under mechanical loading in comparison to the as-received sample.

4. Increase in fracture toughness also resulted after laser peening from $2.32 \mathrm{MPa} \mathrm{m}^{1 / 2}$ to a $3.29 \mathrm{MPa} \mathrm{m} \mathrm{m}^{1 / 2}$ for the applied conditions. Both the increase in hardness, a reduction in the flaw size and the increase in the surface $\mathrm{K}_{\mathrm{Ic}}$ indicated that the laser peened surface may have undergone a level of plastic deformation. This in turn, generated a compressive stress layer under the peened area and so, prevented a deeper and broader penetration of the diamond footprint and expansion of the resulting crack lengths.

In addition, the leading author of this paper further suggest a full residual stress analysis and phase transformation study to understand the laser material interaction during laser peening. 


\section{AUTHOR AFFILIATIONS}

Pratik Shukla, University of Chester, Department of Mechanical Engineering, Laser Engineering and Manufacturing Research Group, Faculty of Science and Engineering, Thornton Science Park, Chester, CH2 4NU, UK.

Graham C. Smith, University of Chester, Department of Natural Sciences, Laser Engineering and Manufacturing Research Group, Faculty of Science and Engineering, Thornton Science Park, Chester, $\mathrm{CH} 2$ 4NU, UK

David G. Waugh, University of Chester, Department of Mechanical Engineering, Laser Engineering and Manufacturing Research Group, Faculty of Science and Engineering, Thornton Science Park, Chester, CH2 4NU, UK

Jonathan Lawrence, University of Chester, Department of Mechanical Engineering, Laser Engineering and Manufacturing Research Group, Faculty of Science and Engineering, Thornton Science Park, Chester, CH2 4NU, UK.

\section{REFERENCES}

1. Clauer H. A., "Laser shock peening for fatigue resistance in surface treatment of titanium alloys," The Metal Society of AIME Conference, 217-230 (1996).

2. Peyre, P., Merrien, P., Lieurade H.P., and Fabbro, R., "Laser induced shock wave surface treatment for 7075-T7351 aluminium alloys," Surface Engineering, 11(1), 47 - 52 (1995).

3. Chen, H., Kysar, J. W., and Lawrence, Y.Y., "Characterization of plastic deformation induced by micro-scale laser shock peening," Journal of Applied Mechanics (ASME), 71, 713- 723 (2004).

4. Kalainathan, S., Sathyajith, S., and Swaroop, S., "Effect of laser shot peening without coating on the surface properties and corrosion behavior of 316L steel," Optics and Lasers in Engineering, 50(12), 1740-1745 (2012).

5. Jiang, S. Q., Zhou, J. Z., Fan, Y. J., Huang, S., and Zhao, J. F., "Prediction on Residual Stress and Fatigue Life of Magnesium Alloy Treated by Laser Shot Peening," Advances in Materials Manufacturing Science and Technology XII, Vol 1: Advanced Manufacturing Technology and equipment and Manufacturing Systems and Automation, Materials Science Forum, 626-627, 393-398 (2009).

6. Mannava, R. S., Bhamare, S., Chaswal, V., Felon, L., Kirschman, D., Lahrman, D., Tenaglia, R., Qian, D., and Vasudevan, V., "Application of laser shock peening for spinal implant rods. International Journal of Structural Integrity," 1757-9864 (2010).

7. Steen, W., Mazumder J., [Laser Material Processing] Fourth Edition, 2010, Springer-Verlag Publication Ltd: London.

8. Gao, Y.K., "Improvement of fatigue property in 7050 - T7451 aluminium alloy by laser peening and shot peening," Material Science and Engineering A, 528, 3823 - 3828 (2011).

9. Goran, I., [Advances in Laser Shock Peening Theory and Practice Around The World] 2011, Volume 2, Issue 1: Emerald Group Publishing Limited, Bingley: United Kingdom.

10. Dongkyun, Lee., [Feasibility Study on Laser Micro welding and Laser Shock Peening Using Femtosecond Laser Pulses] Biblio Bazaar, LLC, Charleston, South Carolina, USA (2011)

11. Dongkyun, Lee., [Feasibility study on laser microwelding and laser shock peening using femtosecond laser pulses] Doctoral Thesis, The University of Michigan, U.S.A, (2011). 
12. Koichi, A., Yuji, S., Kazuma T., Hirotomo T., Shin I. O., "Strengthening of $\mathrm{Si}_{3} \mathrm{~N}_{4}$ Ceramics by Laser Peening," Residual Stresses VII, ECRS7, Volumes 524 - 525, 141-146 (2006).

13. Ding. K., Ye, L., [Laser shock peening Performance and process simulation] Woodhead Publishing: Sawston, Cambridge (2006).

14. Shukla, P.P, Swanson, T.P., Page J.C., "Laser Shock Peening and Mechanical Shot Peening Processes Applicable for the Surface Treatment of Technical Grade Ceramics: A Review," Proceedings of the Institution of Mechanical Engineers Part B: Journal of Engineering Manufacture, 228 (5), 639 - 652 (2014).

15. Shukla, P.P., Lawrence, J., "Fracture toughness modification by using a fibre laser surface treatment of a silicon nitride engineering ceramic," Journal of Materials Science 45 (23), 6540-6555 (2010).

16. Shukla, P.P., Lawrence, J., Wu, H., "On the fracture toughness of a zirconia engineering ceramic and the effects thereon of surface processing with fibre laser radiation," Proceedings of the Institution of Mechanical Engineers, Part B, Journal of Engineering Manufacture 224 (B10), 1555-1570 (2010).

17. Shukla, P.P., Lawrence, J., "Evaluation of fracture toughness of $\mathrm{ZrO}_{2}$ and $\mathrm{Si}_{3} \mathrm{~N}_{4}$ engineering ceramics following $\mathrm{CO}_{2}$ and fibre laser surface treatment," Optics and Lasers in Engineering 49 (2), 229 - 239, (2011).

18. Tamhankar, A., and Patel, R., "Use of Short Pulse Width Laser for Maximum Material Removal Rate," The $29^{\text {th }}$ International Congress on Applications of Lasers and Electro-Optics (ICALEO 2011): Laser Materials Processing, 23 - 27 October 2011, Orlando, FL., USA, Paper No: M601, Laser Institute of America (2011). 